\title{
Las aulas, los patios,... fueron construidos para dignificar al hombre, la dictadura militar les cambió el destino...
}

\author{
Alicia Alderete \\ (Escuela de Ciencias de la Educación) \\ (Universidad Nacional de Rosario. Argentina)
}

\section{Resumen}

Esta investigación fue realizada para el Área del Currículum II de la Carrera de Ciencias de la Educación, teniendo como objeto de estudio al Instituto Secundario perteneciente al Complejo Educativo y Cultural Constancio Vigil. Este Complejo tuvo origen en los años ' 50 en la Zona Sur de Rosario; siendo causa y consecuencia de las necesidades de los habitantes de Tablada y Villa Manuelita. Estos barrios debieron generarse sus propias instituciones porque, ya en esos tiempos, el Estado se desvinculaba en lo que concierne a Cultura y Educación en los sectores de modesta condición.

Se enmarcó al trabajo entre los años 1970-1983. Es en marzo de 1970 cuando el Secundario inicia sus actividades que se ven coartadas luego del 24 de marzo de 1976 cuando los Militares toman la conducción de nuestro país. Este autoritarismo interviene el Complejo el 25 de febrero de 1977. El retorno a la Democracia en 1983 lo encuentra en manos de autoridades provinciales y totalmente fuera de los ideales que la crearon y habitaron.

Innovaciones educativas, cortes y consecuencias, es lo que se intentó analizar desde la empiria, documentos "caseros" y artículos de diarios.

\section{Palabras clave:}

Currículum - Innovación - Cultura Institucional - Dictadura - Crisis.

\section{Summary}

This investigation was realized for Curriculum Area II of the Sciences of Education Career, taking like object of study the high school institute belongs to the Educative and Cultural College Costancio Vigil. This College had its origin in the '50 years in the south town of Rosario city; being cause and consequence of needing of Tablada and Villa Manuelita residents. These neightbourhood must to generate its own institutions because upon those times the government overlooked cultural and educative politics for the sectors of most poverty. 
This work was framed between the years 1970-1983. On march 1970 the high school begins its activities but they were interrupted on march 24 of 1976, when the military forces took the conduction of our country and intervened the College on february 25 of 1977 . The return to democracy in 1983 found it in power of province government and outside of the ideals than created.

Educative innovations, breaks out and consequences were analysed from the empiria, "homely" documents and newspaper articles.

\section{Key words:}

Curriculum - Innovation - Institutional culture - Dictature - Crisis.

\section{Introducción}

El tema que vertebra este trabajo de investigación se titula: "Innovaciones que se produjeron a nivel institucional y curricular en el Instituto Secundario "Constancio C. Vigil" y sus posteriores modificaciones en las décadas de 1970 a 1983".

Ha sido realizado desde septiembre de 2008 y aprobado en marzo de 2009 para el Área del Currículum II, perteneciente al $4^{\circ}$ año de la Carrera de Ciencias de la Educación de la Facultad de Humanidades y Artes (U. N. R.).

En su desarrollo se pretende indagar acerca de una de las experiencias educativas populares de mayor envergadura de América Latina. Se trata del Complejo Educativo y Cultural Constancio C. Vigil de la ciudad de Rosario. Fue creado en los años '50 por los habitantes de Tablada y Villa Manuelita, barrios de la Zona Sur de la misma ciudad. Como este Complejo Barrial contaba con un gran número de instituciones y dependencias en su interior, se recortó el problema tomando como objeto de estudio al Instituto Secundario. Éste, como las demás instituciones del Complejo, fue creado desde las necesidades de las gentes... de los obreros laboriosos de esos humildes barrios del sur... quienes no fueron escuchados por el Estado cuando aún lo que peticionaran se tratara de Educación y Cultura. Por estas razones, tuvo que pertenecer al subsistema de enseñanza Privada, pero gratuito en su práctica pedagógica. Su crecimiento fue tal que contrastó con una sociedad hipócrita que abrazaba los derechos populares en las leyes pero que los negaba en la práctica. La llegada, el 24 de marzo de 1976, de la última Dictadura Militar en nuestra Argentina dividió al Complejo, luego del 27 de febrero de 1977, cuando los jefes militares lo intervienen, en dos mitades: un antes y un después.

De lo que se trató, entonces, fue de investigar sobre las innovaciones que se produjeron en el Currículum como norma y en el Currículum como 
práctica en el Secundario, pudiéndose acceder sólo al segundo de ellos mediante fuentes empíricas. El Currículum como norma fue destruido por esas autoridades militares interventoras. El estudio de dicho Instituto se organizó en tres partes: las innovaciones que se produjeron en el área educativa, la Intervención del Complejo, y las consecuencias y modificaciones que ésta produce; enmarcándonos entre los años 1970-1983.

Por cuestiones de límites en la extensión que deben tener los trabajos presentados en esta Revista, no explicaremos detalladamente los Marcos Teórico y Metodológico. Los autores y conceptos que se trabajaron en el primero los citaremos en el Desarrollo del Trabajo, los cuales fueron utilizados para analizar el contexto en que tuvo lugar el Complejo y la función educativa del Instituto Secundario.

Con respecto al Marco Metodológico, aclaremos que fue realizado desde el Paradigma Cualitativo (1), y se enmarcó dentro de lo que Mc Kernan (1999) define como "Estudio de Casos" (2). Los métodos utilizados para el relevamiento de información fueron la entrevista en profundidad semi-estructurada a personas que de una u otra forma estuvieron vinculados al Complejo y al Secundario en particular, el análisis de documentos, bibliografía existente sobre la historia de La Vigil, artículos de diarios de la época y documentación "casera" (3), que ayudaron a reconstruir el pasado reciente del Instituto.

El trabajo de investigación originariamente contaba con cuatro Capítulos (4), aquí lo desarrollaremos de manera conjunta y obviando gran cantidad de matices, sin ser por ello menos interesante.

\section{Desarrollo}

En 1944, en la Zona Sur de la ciudad de Rosario, se constituye por obra de los habitantes de Barrios Tablada y Villa Manuelita (unas de las primeras villas miserias de la década del '40), una Sociedad Vecinal. "Lo habitaba (...) gente humilde que trabajaba que en su mayoría en las fábricas de la zona, vinculadas a la industria frigorífica, otros operarios se desempeñaban en aserraderos, en depósitos de materiales de construcción o en el puerto" (5).

También vivía allí "Salvador Castro, carbonero de oficio, portugués de nacimiento y de condición analfabeto" (6) que recorría las viviendas del vecindario, y allí descubrió revistas y libros de lectura circunstancial. Un día se animó y los pidió para la vecinal" (7).

Comenzó a ganar espacio, de este modo, un viejo armario con libros y revistas de la misma calidad. La lectura fue acercando a los jóvenes, a la vez que la bibliografía avanzaba en su crecimiento, así la Vecinal inau- 
gura otra sección: la Biblioteca. Esta misma juventud es la que en 1957, la denomina formalmente: "Constancio C. Vigil" (8).

En 1956 se organiza desde la institución una rifa para destinar esos fondos a la adquisición de material bibliográfico; a la vez que se promueve e incrementa el ingreso de nuevos socios.

Como las actividades que allí tenían lugar excedían las posibilidades del espacio físico, en 1963 se inaugura en la calle Alem 3078 un edificio de tres plantas.

La Biblioteca Vigil da origen respectivamente en los años posteriores al Jardín de Infantes, a la Universidad Popular, al Instituto Secundario y a la Escuela Primaria, entre otras. Se organiza de esta manera, un Proyecto Educativo y Cultural popular, o al decir de Rubén Naranjo (1990-93), se trató de un "proyecto educativo moderno y respetuoso de los derechos del niño y el adolescente" (9).

El Complejo Educativo y Cultural C. C. Vigil surge dentro de una Argentina sacudida por acontecimientos sociales, políticos y culturales que sin lugar a dudas influyeron en sus instituciones. La historia por la que se vio atravesado nuestro país hizo que el Proyecto Educativo en el complejo tuviera vigencia auténtica aproximadamente 8 años. Ello se debió a la intervención que sufren como organización en febrero de 1977, por parte del gobierno dictatorial asumido en 1976.

A continuación desarrollaremos desde un ordenamiento cronológico los hechos que sucedieron en el plano nacional y en el Complejo Vigil en la década del '70. El punto de partida estará situado en la inauguración del Instituto Secundario.

\section{El instituto Secundario}

"Los vecinos solicitaron y trabajaron para la creación de la secundaria -no había ninguna en el barrio y en toda la zona sur sobre su límite ribereño- y después de lograrla se empeñaron en tener la primaria" (10), completándose así todos los niveles de la escolaridad.

Reconocido por el Ministerio de Educación y Justicia de la Nación; el Secundario es incorporado a la Enseñanza Oficial con el Registro N ${ }^{\circ} \mathrm{C} 188$ en la Secretaría Nacional de Enseñanza Privada (S. N. E. P.).

Con sede en la ochava de las calles Alem y Gaboto, y en un edificio de $8.000 \mathrm{~m} 2$, comienza a funcionar el 16 de marzo de 1970, registrándose un ingreso de 163 alumnos y estableciéndose para este $1^{\circ}$ año seis divisiones de cursado. 
El moderno edificio, construido por los Arquitectos Caggiano y Abate, se encontraba equipado de mobiliario necesario y suficiente para las tareas de enseñanza y aprendizaje y contaba con:

- Rampas de ingreso pensadas en relación a la asistencia de alumnos con discapacidades en la motricidad gruesa;

- Veinticinco aulas con bancos y sillas con ruedas;

- Sala de profesores;

- Laboratorios;

- Bibliotecas con materiales tanto para profesores como para los alumnos, llegándose a tener aproximadamente 50.000 volúmenes (11). Además de la Biblioteca Central, cada institución poseía una biblioteca, atendida por profesionales graduados, en su mayoría de establecimientos oficiales;

- Museo;

- Gimnasio cubierto y dos semidescubiertos equipados con elementos pertinentes para la actividad física;

- $\quad$ Sala de música con instrumentos para tal fin;

- Patios;

- Consultorios Médicos proveídos de instalación básica para atención primaria.

\section{1. a. Modalidad educativa}

El régimen de estudio estaba apoyado en la doble escolaridad (propio de los establecimientos privados), pero por el contrario, se ofrecía enseñanza pública y popular.

El cursado se dividía en 7 horas por la mañana y 3 por la tarde. Al programa oficial del nivel de enseñanza secundaria se agregaban temas como: "Estudio Dirigido, Mecanografía, Técnica Museológica, cursos de Computación y Práctica de Perfoverificación y Física Integrada" (12).

Los alumnos asistían hasta el $3^{\circ}$ año al ciclo básico del bachillerato, diversificándose luego en las siguientes terminalidades de validez nacional: Perito Mercantil, Bachillerato Común, Bachillerato en Ciencias Biológicas y Bachillerato en Ciencias Físico-Matemáticas.

Para los adolescentes provenientes de familias carenciadas, se estableció el otorgamiento de pasantías remuneradas que consistían en tareas en las áreas de Producción, Administración y Educación realizadas por el alumno en su Instituto en contraturno al cursado. 


\section{1. b. Currículas}

Se elaboraron en colaboración con los estudiantes siendo dinámicas y actualizadas periódica y permanentemente. Las clases no eran solamente teóricas sino también prácticas.

"La doble escolaridad permitió incrementar dos horas de inglés y una de biología, en el plan de materias exigidas por la Nación, agregándose una hora de contabilidad práctica, una de caligrafía y cinco de estudio dirigido" (13).

Además de las materias del programa oficial, existían otras que eran complementarias y de cada orientación, un ejemplo sería Taxidermia, propia de la terminalidad en Ciencias Biológicas.

En el año '74 se realizó un relevamiento sobre los intereses del estudiantado, los cuales votaron proyectos y temas de gran importancia como: los problemas generacionales o de relación familiar. En el $2^{\circ}$ año se aprendía acerca del desarrollo del niño hasta la adolescencia, desarrollándose profundamente esta última en el $3^{\circ}$ año. En los dos últimos años de Instituto $\left(4^{\circ}\right.$ y $\left.5^{\circ}\right)$ se dictaban cursos de orientación vocacional.

\section{1. c. Los alumnos}

Hacia los años '70, el Complejo Vigil contaba con una matrícula de 3.000 alumnos, entre los que se encontraban infantes, niños, adolescentes y adultos (éstos últimos en la Universidad Popular). Lo anteriormente dicho demandó tareas de coordinación y sincronización que condujeron a la formulación del decálogo denominado "Los Principios Educativos" (14), conteniendo en sus líneas las ideas básicas del Complejo. En su interior se plasmó y evidenció "el profundo respeto por las personas y el reconocimiento de sus auténticos derechos a la educación" (15).

Los alumnos conformaron en 1973 el "Centro de Alumnos del Instituto Secundario", organismo interno que tenía la posibilidad de participar en todas las reuniones efectuadas por el Departamento de Educación. Ello permitía el intercambio entre distintas generaciones y la comprensión de los problemas sociales generales.

Formaron también con los profesores el "Consejo Asesor", elegido año a año mediante elecciones y luego cada lista (también compuesta por alumnos y docentes) presentaba los proyectos a realizar el período lectivo siguiente (16).

Los estudiantes eran atendidos y escuchados abiertamente por las autoridades, recibiendo amplias respuestas por parte de ellas y sin ningún tipo de censura. 


\section{1. d. Los Profesionales}

- Departamento de Educación: Para su organizado funcionamiento, el Jardín de Infantes, la Escuela Primaria, el Instituto Secundario, además de otras escuelas, talleres y cursos, constituyeron lo que fue el Departamento de Educación; "organismo centralizador y coordinador de todas las actividades educativas" (17). La Dirección del Departamento le fue confiada a Mario López Dabat, Maestro Normal que fue testigo de la "noche de los bastones largos", situación social en 1966 lo obliga a apartarse de su cargo directivo en la Escuela de Filosofía de la Facultad de Humanidades y Artes de la U. N. R.

- Rector: En el Secundario, éste remitía a lo que las demás escuelas llamaban Director del Establecimiento. La Primera Rectora del Instituto fue María Callegari, la sucedió Héctor Bonaparte y posteriormente se desempeñó en el cargo Edgardo Osanna. El último Rector fue el Artista Plástico Prof. Rubén Naranjo, obligado por los Interventores a renunciar en abril de 1977.

- Los Profesores: Eran tomados por concurso ante un tribunal evaluador, el Gabinete Psicopedagógico y el Rector. Se los evaluaba de acuerdo al Perfil Profesional pretendido por el Complejo. Debían ser abiertos, flexibles, innovadores y democráticos. Se elaboraba un escalafón y se los designaba en los cargos. El sueldo percibido por los mismos superaba el básico del oficial (18).

El grupo de profesionales "debía" perfeccionarse con el fin de poder responder a las exigencias que demandaban las tareas de enseñanza y aprendizaje. Pero no se dejaba a los mismos librados en su especialización, sino que se les brindaba los medios necesarios para poder llevarla a cabo. En su gran mayoría las capacitaciones eran los días sábados, para no interrumpir el aprendizaje de los alumnos los días hábiles. Las mismas eran costeadas por el Complejo. Al profesor se le abonaba en horas extras su concurrencia, ya que ella no estaba contemplada dentro de su paritaria mensual.

- Existían los cargos de Directores de Curso: "La estructura pedagógica del instituto secundario se apoyó en la tarea realizada por los directores de curso (...) que se desempeñaron en los tres primeros cursos y mantenían permanente relación con los estudiantes (...)" (19).

Estos espacios eran cubiertos por psicólogos, psicopedagogos o estudiantes próximos a recibirse en dichas carreras.

Los Directores de Curso tuvieron a su cargo la materia denominada "Estudio Dirigido", con el fin de facilitar la experiencia educativa. El 
estudio en grupos, la interpretación de los textos, elaboración de resúmenes y síntesis, fueron algunas de las prácticas llevadas a cabo en este espacio extra-curricular.

Todo esto permitió conocer las preocupaciones de los estudiantesadolescentes, pudiéndose así asesorarlos en el análisis y superación personal y social.

En los dos últimos años de escolaridad media ( $4^{\circ}$ y $5^{\circ}$ año) ya no se cursaba el Estudio Dirigido, sino la Orientación Vocacional, dictada por profesionales que tenían a su cargo indagar sobre las vocaciones y destinos de los estudiantes, para asistirlos y prepararlos en su próximo ingreso al nivel superior de la enseñanza, o al mundo del trabajo.

- $\quad$ El Gabinete Psicopedagógico: conformado también por Profesionales en Psicología y Educación encargados de detectar las problemáticas de aprendizaje, que en su mayoría se vinculaban con historias de familias que nunca habían accedido a la educación media y por lo tanto no poseían experiencias que facilitaran la escolaridad de sus hijos.

- Los Consultorios Médicos de Asistencia Primaria: cada institución contaba con consultorios integrados por médicos, odontólogos, fonoaudiólogos, enfermeros, deportólogos (20).

El total del personal del Instituto sumaba 62 Profesores, 12 Directores de Cursos, 7 Preceptores y 9 Auxiliares.

\section{1. e. Otros espacios que ayudaron al crecimiento de los alumnos}

El equipamiento de ambientes, instrumentos, elementos y profesionales trabajando hicieron posible los cursos de Artes Visuales, Cerámica, Artesanías, Música, Ajedrez, Expresión Creadora y Mecanografía.

Dentro de los equipos audiovisuales, se logró adquirir en la óptica Zeiss, de Alemania Federal, un telescopio doble "coudé", lo que permitió efectuar cursos de Astronomía y tareas de investigación en diversas áreas, siendo de gran importancia la vinculada al seguimiento de las manchas del sol en un programa requerido por la UNESCO.

\section{1. f. Decálogo}

El Complejo Constancio Vigil elaboró un decálogo que lo definió como "Principios Educativos de la Biblioteca Popular Constancio C. Vigil", con el objetivo de sentar las bases de esa educación popular que pretendía. Surgió desde y fue utilizado por las bases de la sociedad, ella lo creó y en ella permaneció. En el Decálogo se destacó la gran importancia de la edu- 
cación "continua" en la formación de los hombres, mujeres y niños, tanto en lo que respecta a la educación formal (21), y educación no formal (22), la recreación (23), y la cultura.

Para asegurar la escolaridad de los alumnos, se contaba en la escuela primaria con maestras niveladoras que ayudaban a niños con problemas de aprendizaje, en el instituto secundario se creó el cargo de Directores de Curso ya explicitado. También existía el libre acceso a las bibliotecas. Por todo ello, la deserción no tenía cabida, ya que los medios para la escolarización estaban destinados. Se puede hablar de una deserción de casi 0 (\%) (24).

El pueblo la creó y por eso fue un mal ejemplo para la dictadura. El Complejo fue una respuesta del trabajo de los desposeídos y en el que las diferencias no fueron un impedimento. La premisa no era excluir; sino incluir $y$, sabemos, se la defendió hasta las últimas consecuencias.

Luego de esta breve pero clara descripción del Instituto Secundario, y después de haber analizado algunos de sus aspectos, observemos seguidamente las tendencias educativas que circulaban a nivel nacional comparándolas con el trabajo de enseñanza y aprendizaje que tenían lugar en la institución de enseñanza media.

\section{La educación en los ' 60 y en los ' 70}

Retomemos nuestra educación nacional desde aproximadamente la década de 1960, con el fin de establecer algunas causas y consecuencias de la enseñanza que va a ir perfilándose en la sociedad. Tengamos presente que la educación ha sido siempre objeto de las políticas estatales utilizándola como medio para transmitir su ideología, formando así una población que respondiese a sus necesidades.

En las presidencias de Perón (1946-55) se había llegado a educar a las masas populares en su gran mayoría. Desde un lugar optimista podríamos agregar que se satisface casi en su totalidad la enseñanza primaria. La ansiada "homogeneización" estaba casi saldada y los porcentajes de alfabetización eran elevados. Se comienza a vislumbrar un interés referido a la educación media, ya que existían lógicas contrapuestas en relación a ambos niveles del sistema educativo: "(...) mientras en nivel primario respondió a la lógica de la homogeneización, el nivel medio respondió a la lógica de la diferenciación (...)" (25). En otras palabras, de la población que egresaba de la primaria, más de la mitad no ingresaba a la secundaria por diferentes cuestiones (económicas, culturales, sociales o geográficas). 
En los años '60 influyen en las tendencias educativas nacionales el pensamiento filosófico y pedagógico de Saúl A. Taborda y de Juan Mantovani (26).

A comienzo de dicha década tiene lugar el desarrollo de experiencias pedagógicas democráticas, "un nuevo liberalismo laico, escolanovista, muy influido por el psicoanálisis y la psicología social, se desarrolló en jardines de infantes, colonias de vacaciones, campamentos y centros de recreación" (27). Algunas escuelas públicas se hicieron eco e implementaron reformas tales como doble escolaridad. Influyentes de ello fueron educadores de izquierda como Luis Iglesias y Rosa Ziperovich. La educación popular también se genera y consigue un espacio en la sociedad, practicándose en su mayoría en zonas marginales.

En 1966, el presidente Juan Carlos Onganía, con la necesidad de instaurar el orden nacional interrumpe dichas experiencias educativas. El saldo que nos deja este gobierno es un violento ataque ideológico a la docencia y a la Universidad pública (28).

Durante el período de Lanusse (1971-73), las experiencias de educación popular, originadas en los '60 revivieron, configurándose una pedagogía sintetizada de las experiencias de la Escuela Nueva, de Paulo Freire y de la izquierda.

Recordemos que los habitantes de Tablada, reaccionarios ante un Estado que ya los desatendía como sujetos sociales con derechos, no tuvieron otra opción que organizarse y crear sus propias instituciones. Pensaron una educación diferente a la que los había excluido, de esta manera idearon una escuela que trabajara como un verdadero "espacio ecológico de cruces de culturas" (29).

Las teorías pedagógicas que orientaban y delineaban la educación del Instituto Secundario C. Vigil no pertenecían a las de corte tradicional, arraigadas en el imaginario educativo de la época. Por el contrario, el escolanovismo y las teorías críticas eran las influyentes en el Instituto. Aquí las experiencias educativas ocupaban un espacio innovador, tanto en lo pedagógico como en lo arquitectónico (ya detallado en párrafos anteriores).

El término Innovación encuentra relación con lo nuevo, lo actual; ligado al cambio, a la apuesta sobre lo desconocido, lo diferente. Abordemos el concepto de innovación desde Brovelli (2006), quien teoriza: "Podemos afirmar que la innovación educativa se refiere a un cambio, intencional, deliberado, con sentido, que permite romper con una situación convencional e implementar otra. Es una forma de abrir ventanas, iniciar caminos hacia nuevas posibilidades" (30). Consideramos importante este concepto, ya que en Vigil, justamente lo que se hizo fue mezclar diferentes concepciones, 
modelos y paradigmas con el fin de trabajar desde una educación diferente con respecto a las tendencias educativas de las décadas del '50, '60; y '70 en que tuvo lugar como Complejo Educativo y Cultural.

Creemos que esta práctica innovadora en el Complejo tuvo más que ver con una decisión de sus actores institucionales que intentaban dar respuestas a los problemas sociales, educativos, políticos y culturales; que con las políticas educativas castradoras de las décadas anteriormente mencionadas.

En lo que respecta a las prácticas institucionales, se fundamenta si describimos la cultura institucional para Lidia Fernández (s.f.):

“(...) La interacción de los componentes básicos a lo largo del tiempo arroja como resultado una serie de productos materiales y simbólicos que, en forma genérica, llamamos cultura institucional" (31). Dentro de dicho concepto la autora ubica:

- El Modelo institucional: Derivado en parte de los modelos generales, recibe y expresa las características elaboradas en la historia propia del establecimiento, y los niveles de las formas de funcionamiento deseadas.

- La ideología institucional: Conformada por la organización de concepciones y representaciones que justifican el modelo y el estilo que éste expresa.

Anteriormente se describió el criterio de selección de los Profesionales que formaron parte del Complejo Vigil. Ello, sin lugar a dudas, generó un cierto clima de consenso en lo que respecta a los ideales que se perseguían en el Instituto en particular y en el Complejo en general.

El respeto por los niños y los adolescentes se ponía en práctica mediante una educación que respetaba y trabajaba con y desde la cultura del alumno; problematizando la historia personal y la historia oficial. La educación tenía de esta manera un accionar político. El enfoque pedagógico del educador brasileño Paulo Reglus Neves Freire, menciona que los problemas de la educación no son metodológicos ni pedagógicos, sino políticos. Citemos a Carlos Alberto Torres (2002) quien escribe:

"Los programas educativos que se diseñan inspirados en este modelo (...), tratan de constituirse en instrumentos o mecanismos de colaboración político-pedagógica con los sectores socialmente subordinados. Es una pedagogía para la transición social, y por lo tanto define su actividad educativa como una "acción cultural" cuyo objetivo central puede resumirse en el término "concientización”. (...) En términos estrictamente educativos, su intención 
es una pedagogía no autoritaria. Docentes y estudiantes son a la vez estudiantes y docentes, con status similar, y están vinculados por un diálogo pedagógico caracterizado por una relación horizontal. El programa educativo puede llevarse a cabo tanto en un aula como en un "círculo de cultura", y la transmisión de ideas y conocimientos sucede a partir de compartir "el conocimiento del conocimiento anterior" de los educandos" (32).

Con respecto a ello, los entrevistados han mencionado el carácter no autoritario, informal pero respetuoso de las relaciones entre el profesorado y los alumnos. Los datos empíricos también nos han informado sobre las experiencias educativas escolares con materiales no convencionales y actividades de distinta índole que ponían en evidencia el accionar conjunto de los adolescentes y sus docentes en relación a la selección de algunos contenidos curriculares, bibliografía, materiales didácticos (33).

Lo anteriormente dicho da cuenta de una pedagogía "negociada", donde los alumnos podían poner en acto sus aprendizajes de la vida cotidiana, académicos, oficiales y críticos. Estos últimos lograron instalarse en la conciencia estudiantil a causa de las características relacionales de la escuela.

El concepto de enseñanza que circulaba en la institución tenía fuertes connotaciones políticas e ideológicas críticas, ello era reforzado mediante el material de trabajo seleccionado. La Profesora entrevistada que tenía a su cargo el espacio curricular "Historia" nos decía al respecto:

"Nosotros seleccionábamos el material de trabajo con toda libertad... hacíamos una especie de cuadernillos donde sacábamos de algún autor lo más importante... cuando todas las escuelas de Rosario trabajaban con manuales, nosotros en Historia hacíamos una selección de libros de Paidós donde escribía Halperín Donghi... recuerdo una vez que me fue a observar Naranjo, yo para trabajar el Barroco seleccioné unas pinturas, trabajé desde el Arte..." (34).

Este breve fragmento da cuenta de la negociación del currículum entre los sujetos institucionales, considerando de esta manera al "Currículum como una construcción social" (35). Deja apreciar también el estudio de la Historia desde uno de los autores críticos de Argentina; además del uso del Arte en el aula, donde lo estético entra en el juego del aprendizaje, y retira a la tríada didáctica de lo típico y común (36).

En lo que respecta a la Evaluación, durante la segunda mitad del siglo XX, permanecía en la esfera de la educación una práctica evaluadora 
reduccionista vinculada a la obtención de los objetivos deseados desde la planificación del docente. Con las ansias puestas en la objetividad, sólo se enmascaraba una educación que reproducía las relaciones de dominación necesarias para mantener el statu quo.

Desde la teoría crítica, la Evaluación va a perfilarse como una instancia en la que el docente va a comprometerse éticamente con la práctica, siendo también evaluado al igual que los estudiantes. Aquí, la evaluación es útil tanto para reflexionar sobre los aprendizajes construidos por los alumnos, como también una instancia de evaluación del docente sobre su propia práctica. Cuando las tendencias educativas de la época estaban vinculadas al tecnicismo, en Vigil los profesores debían evaluarse a sí mismos e incluir en el Currículum los intereses de los estudiantes.

La continuidad entre niveles del sistema educativo fue otro aspecto de gran importancia que sin dudas pudo haber contribuido a esta secuencia de innovaciones por parte del Complejo Educativo. La integración y continuidad consistió no sólo en la existencia de escuelas correspondientes a cada uno de los niveles, sino por articulación que les dio el "departamento de educación único". Éste funcionaba con representantes de cada una de las instituciones del Complejo, lo que ayudaba a un acuerdo interinstitucional en relación a los contenidos a trabajar. Pero el Proyecto se vio coartado por los Interventores, ya que no existió promoción de escolares que pudieran comenzar en el Jardín de Infantes, transitar la Primaria y culminar la Secundaria dentro del Complejo. Es decir, el Proyecto de Educación Formal de Vigil tuvo vigencia auténtica durante 8 o 9 años. En adelante, con la ejecución de la intervención, muchos alumnos abandonaron, se retiraron y algunos hasta desaparecieron.

Son las escuelas, como instituciones sociales, las que poseen la capacidad de contribuir al cambio, los cuales dependen y deben ser sostenidos desde las gestiones centrales. La burocracia autoritaria vigente oficialmente en la Argentina desde marzo de 1976, no estuvo dispuesta a aceptar las innovaciones y cambios educativos que se practicaban en Vigil, Ilevando a cabo la interrupción de las actividades el 27 de febrero de 1977.

\section{La Intervención}

El golpe militar del 24 de marzo de 1976, que derrocó a Isabel Perón y se mantuvo en el poder hasta 1983, "utilizó al sistema educativo como una estrategia de disciplinamiento social y control ideológico, pregonando la unidad nacional a través de la uniformidad del pensamiento y las prácticas ritualizadas de la currícula escolar" (37). 
Franz Neumann (s.f.) propuso definir la dictadura como "el gobierno de una persona o de un grupo de personas que se arrogan el poder dentro del estado y lo monopolizan, ejerciéndolo sin restricciones" (38). A su vez distingue tres tipos de dictadura: la forma simple, cesarista y totalitaria. Es esta última la que describe a la que tuvo lugar en la Argentina en los años '70: "En la dictadura totalitaria, finalmente, a los rasgos de las otras dos formas se añade el control de la educación, de todos los medios de comunicación, y el uso de las técnicas coercitivas ad hoc, con la pretensión de establecer un control "total"' (39).

Fue precisamente este control total de la sociedad el objetivo del Proceso de Reorganización nacional que apuntó al campo de la educación y la cultura, aunándolos bajo el nombre de Ministerio de Cultura y Educación, para "atacar" fácilmente aquello que quería cambiar. Se comenzó por detallar la lista de libros que no se podían leer, se los incineró -y de esto Vigil tiene un gran número (40)- y se cambiaron las currículas.

En los documentos oficiales se prohibían obras como las del pedagogo Paulo Freire, por su ideología marxista, entre otros.

El Ministro de Cultura y Educación Pedro Bruera organizó la oficina de "Recursos Humanos", donde existían agentes de inteligencia con la misión de infiltrarse en espacios educativos y culturales para detectar "subversivos" (41). Dicha tarea de detección y posterior exterminio físico de opositores en el campo educativo y cultural tuvo el nombre de "Operación Claridad".

Tablada: Barrio obrero, constituido por trabajadores sindicalizados y conocedores de sus derechos sociales, acostumbrados a reivindicarse y luchar para conseguir lo que les pertenece (como la educación) y decididos a alcanzar cuanto se propusieran. La creación del Complejo es un ejemplo de sus ideales logrados. Por generarse contactos con diferentes puntos del mundo (Cuba, Alemania), han sido considerados "Comunistas". Por trabajar desde y con la cultura obrera, han sido tildados de "subversivos". Por enseñar en y para la libertad, poniendo bajo la lupa los postulados de la clase hegemónica, han sido condenados "marxistas". Por todo ello los docentes y alumnos de los cursos elevados del Instituto Secundario vivieron esos operativos desde dentro.

Luego de "avisos" mediante ataques de la "Triple A" (42) en el '73 y en el ' 75 , el 27 de febrero de 1977, aproximadamente a las diez de la mañana, personeros militares irrumpieron en el Instituto Secundario para intervenir la institución, ya que la misma había "confundido las ideas del ser nacional".

Esta dictadura corrupta y genocida que se arrogó el poder sin restricciones, fue la que "(...) cumpliendo con el Decreto 0942/77 de la Intervención, 
dictado entre gallos y media noche por el gobierno de facto de la provincia de Santa Fe" (43), ejecutó la Intervención del Complejo. El gobernador de nuestra provincia, vicealmirante Jorge A. Desimone y la Resolución № 137/77 del Instituto Nacional de Acción Mutual (INAM), dispusieron al capitán de corbeta Esteban César Molina como Interventor Normalizador de la Biblioteca Popular Constancio C. Vigil.

La "razón" por la que se interviene Vigil tiene que ver -a secas- con un problema económico. Como se ha dicho anteriormente, el Complejo no era estatal, ni recibía aportes desde el gobierno. Las personas que allí asistían sólo abonaban una cuota social mínima por ello, desde 1959 tenían organizada una rifa, a la que la crisis de los años ' 70 conocida como Rodrigazo (44) afectó en su totalidad. El shock económico no permitía realizar la compra de los premios a sortear y los fondos no daban abasto para el pago a los empleados del Complejo; por lo que la Comisión peticiona al gobierno una autorización para incrementar el precio de los bonos, pero el Estado no lo autoriza (45). Además la intervención militar puso de pantalla las deudas con respecto a los premios; pero lo que en realidad sucedió se corresponde con el patrimonio con el que Vigil contaba (propiedades en diferentes provincias del país) y con connotaciones de tipo ideológicas: El objetivo real fue la aniquilación del Complejo Biblioteca Vigil (46).

La ayuda oficial que correspondía a las escuelas de educación formal de Vigil posteriormente llegó, pero no al tiempo requerido, sino tres meses antes de la Intervención, pero tampoco lograba cubrir los gastos y deudas del Complejo. Estas dificultades financieras podían haberse solucionado a tiempo. Lo que se ponía en evidencia era que la Institución no era bien vista por el gobierno "que ya había comenzado su amplio plan de exterminio de obras y personas" (47).

\section{La Crisis}

La intervención de las instituciones -luego de haber recibido bombardeos a modo de amenazas-, sin duda instaló en la institución algún sentimiento al respecto.

De esta manera es necesario analizar el contexto en el que se desempeña el Instituto Secundario. Para tal motivo es importante el aporte de Aldo Schlemenson (1993), el que escribe: "los fenómenos de crisis que suelen darse en las organizaciones están relacionados con la influencia de un contexto turbulento amenazante; donde las instituciones deben modificarse o transformarse para evitar el riesgo de desaparición" (48). Con respecto al concepto de crisis, señala el autor: "el contexto turbulento aparece como una dimensión privilegiada que atrae la atención de los participantes, por 
los riesgos y amenazas que connota el impacto. Se incrementan la incertidumbre, la inestabilidad, la confusión y el caos. (...) La crisis supone la ruptura de una regularidad, que impide prever anticipadamente los eventos futuros, cosa que es crucial para la supervivencia" (49).

La investigación realizada demuestra que los cambios que se dieron en el Instituto Secundario no sólo modificaron la tarea educativa, sino también la cultura institucional, donde las ideas que habían erigido y fundamentado al Complejo Biblioteca Vigil, se pusieron en jaque ante la presencia de miembros militares con una ideología totalmente contrapuesta a la que había cimentado al Proyecto.

Al Complejo, el contexto se le manifestaba amenazante, los atentados con bombas, y los secuestros improvisados, las desapariciones ejecutadas (50), logró su máximun con la Intervención e hizo que se instalaran la incertidumbre, inestabilidad, confusión; lo cual se traduce en una crisis, al decir de Schlemenson (1993).

Intervención, secuestros, detenciones, despidos, revisaciones, torturas, liquidaciones, delitos, destrucciones, quemas, arrebatos, desapariciones, son algunas palabras que marcan este momento de crisis en la vida regular de las personas vinculadas con el Complejo y con el Instituto en particular.

Todo lo que hasta entonces, a pesar del contexto turbulento y amenazador, se podía salvar y sobrellevar, desde el día de la Intervención, pasó a ser parte de la incertidumbre, la duda y el desconcierto. Textos escolares que ya no se podían utilizar, material destruido, palabras prohibidas, charlas impedidas, contenidos escolares arrebatados. Al ingresar a la Instituto Secundario, alumnos y profesores debían someterse al control de sus pertenencias y prendas. Las clases eran observadas, un guardia armado circulaba controlando los discursos. Los cabellos cortos, el molinillo que los identificaba como alumnos de Vigil permanecía bajo la ropa con el pánico de ser descubierto. Los alumnos eran citados a la dirección y allí dentro debían dar información sobre profesores y compañeros. El mayor delato de las vidas de las personas, fue -lamentablemente- el sistema utilizado en Biblioteca Central conocido como Newark (51) para el registro de los préstamos bibliográficos. Ello sirvió a los militares como base de datos para investigar a los socios y sus lecturas. "Lo más peligroso verificado en estos procedimientos fue que la entidad mantenía relaciones de canje con la Biblioteca Nacional de Cuba y se recibía la revista "Casa de las Américas" (52). Otro gran cuestionamiento resultó ser la edición del libro "Maestro pueblo, maestro gendarme" de María Teresa Nidelcoff, una obra 
conmovedora y comprometida de la tarea docente en escuelas de zonas marginadas.

Acciones llevadas a cabo:

- Se obliga a los varones a cortarse el cabello;

- Se da de baja a los Directores de Curso;

- Se aplica la Ley de Prescindibilidad a algunos profesores y a otros directamente se los despide. Algunos son secuestrados, otros conservados en su lugar de trabajo;

- Se suspenden los actos escolares con participación de los alumnos;

- Se coartan actividades extracurriculares y la doble escolaridad de los alumnos;

- Se queman cerca de 5.000 libros;

- Desaparecen materiales de alta tecnología del observatorio Astronómico;

- Desaparecen y se destruyen los animales embalsamados del Museo;

- Se queman Currículas institucionales, o departamentales, imponiendo contenidos que no atentaran contra la "Seguridad Nacional".

Sin duda fue una dictadura del tipo "totalitaria", donde además del uso de las fuerzas y la coerción, el control sobre la educación se ejerció con rigidez con la pretensión de establecer ese control "total".

Ocupado el Instituto por las fuerzas militares, son designados por Ramón Telmo Alcides Ibarra en los cargos directivos:

- En abril de 1977: el Dr. Carlos Sfulcini, con el Vicedirector, el Psicólogo Raúl Pangia.

- Julio Adad que ingresa junto con su guardaespaldas Pascual Crisafuli (el que según relatos del personal, circulaba armado por la institución).

- Carlos Viana, quien en la actualidad continúa escribiendo sobre Política, siendo su material editado por el Círculo Militar.

- Marta Pareja de Rodríguez.

- Luisa Kainer, siendo Vicedirectora en su gestión Vilma Donadío.

\section{Ya nada será como antes...}

Con muchos años de paciente y constante trabajo el Barrio levantó una casa para la educación y la cultura, fundada para albergar los cursos y escuelas sin más pretensiones que la utilización plena de sus habitantes. La "Intervención Normalizadora" la convirtió en una cueva burocrática, distinta a los ideales que la forjaron. 
Ya no existía aquel Rector que escuchaba a sus alumnos, a los docentes y aceptaba opiniones. La enseñanza en y de la libertad, pasó a ser disciplinamiento para los estudiantes. Los profesores sabían lo que ya no se podía decir, ni enseñar. Algunos fueron puestos a disposición del Poder Ejecutivo Nacional, otros pasaron a llenar la lista de personas no gratas por haber trabajado en Vigil, lo que los llevó a no conseguir trabajo hasta la vuelta a la democracia. Un grupo de profesores fue preservado en su cargo, pero con ciertas consecuencias (53), algunos de ellos renunciaron, otros fueron despedidos en los años siguientes.

Los alumnos, por su parte, desintegraron el Centro de Estudiantes y los que militaban se fueron; algunos desaparecieron. Las personas que trabajaron en y para un Proyecto Educativo y Cultural respetuoso del niño y el adolescente, lograron, tal vez, una de las mayores experiencias de educación de América Latina. El cúmulo de arrebatos, saqueos, destrucciones, la convirtió en un nido de burócratas... No fue suficiente modificar los objetivos educativos, culturales, sociales, éticos, políticos; sino también le cambiaron el nombre:

En 1981, le designan el nombre de Complejo Educativo y Cultural Pedro de Vega. En el acto para la ocasión, el ministro de Cultura y Educación de Santa Fe, Eduardo Sutter Schneider, expresó "... La idea de un complejo educativo y cultural en la ciudad de Rosario hace más de dos décadas fue plasmada con la creación de la hoy ex Biblioteca Constancio C. Vigil. El gobierno de la provincia, consciente que una de las principales tareas de este Proceso es la de reordenar valores, entendió como conveniente rescatar para esta ciudad y especialmente para una tan populosa como la que nos rodea un proyecto cultural y educativo de gran envergadura que había sido confundido en el tiempo por ideas y motivaciones políticas opuestas a nuestro ser nacional..." (La Capital, 13-09-1981) (54).

Este llamado al ser nacional se utilizó para justificar una aventura de terror infame que afecta letalmente a instituciones barriales. Vigil, en su necesidad de crecimiento, apeló a la gente del barrio: peronistas, socialistas, comunistas, demócratas, y personas sin infiltración política, sin distinciones, haciendo de la práctica democrática su accionar cotidiano...

"Si bien privada, se definió a sí misma como pública, popular, gratuita, laica, pluralista y progresista" (55), con el objetivo puesto en la educación de esa masa de obreros que sabía de sus necesidades, y que por diferentes razones no habían podido apropiarse del conocimiento científico traducido en contenidos escolares. 
Vigil?

¿Qué fue entonces el Complejo Educativo y Cultural Constancio C.

"(...) yo digo que Vigil es "todos los sistemas y ningún sistema", hace su sistema propio (...)" (56).

Posteriormente, y con la vuelta a la democracia en el año 1983, las instituciones de Vigil recuperan dicho nombre. A diferencia, su Biblioteca tiene su espacio físico compartido con la Biblioteca Pedagógica Eudoro Díaz (57), es decir que ya no vuelve a ser la Biblioteca Vigil de los orígenes, pero sus vecinos, la gente del barrio, la siguió reconociendo como... "La Vigil"...

\section{Conclusiones}

"La mayor violación a los derechos de la educación que se realizó en la Argentina fue, sin duda, la intervención y liquidación de la Biblioteca Vigil. (...) El pueblo la creó. Por eso fue un mal ejemplo para la dictadura (...)" (57).

La ardua tarea de investigación, la cual planteó al principio algunas dificultades, consiguió proporcionarnos conocimientos y saberes de experiencias populares de gran envergadura como fue el Complejo Educativo y Cultural Constancio C. Vigil.

Barrios Tablada y Villa Manuelita, zona "brava" por aquellos tiempos, se salió de la monotonía con la que los identificaban desde otras zonas de la ciudad y levantó, allí, en Alem y Gaboto, un edificio de nueve pisos, al que asistieron todos los adolescentes. Era el Secundario, el único en 140 manzanas de superficie.

Los que pensaron al Complejo, sólo pretendían lo mejor para los que allí concurrían. Al recurso económico lo consiguieron desde el esfuerzo de todo aquél que se comprometió y trabajó en él. Fue una obra de gentes que no pretendían llenarse los bolsillos, sino volcarlo en educación popular y en cultura. Por ello, una vez logrados los recursos económicos necesarios, se propusieron invitar y contratar para trabajar a personas, que sabían, contaban con una perspectiva de lo social y cultural que no respondía a la hegemonía, sino que comprendían que existían opresores y oprimidos. Así forman parte de esta experiencia personalidades como Rubén Naranjo, Mario López Dabat, Augusto Duri, Antonia Frutos, Raúl Frutos, Victorio Capolongo, Rubén Martiniano Rodríguez, Teresa Martí, y demás gentes sin historias de héroes ni diplomas que aportaron con su trabajo y colaboraron en la creación y organización de una de las mejores experiencias populares, 
culturales y educativas de América Latina. Pero esto seguramente contrastaba con una sociedad que ya era competitiva, y con gobiernos autoritarios que no estaban dispuestos a aceptar el movimiento social. Para imponer su doctrina necesitaban controlar la educación, la cultura y aún lo más íntimo, la libertad de pensamiento. Es éste el motivo de la intervención de la Vigil del 25 de febrero de 1977.

La educación en y para la libertad debió sofocarse. Lo nuevo, lo diferente, lo heterogéneo, se defendió como se pudo y hasta donde se pudo. La dictadura militar arrasó con todo, y el saldo fue una sociedad atravesada por el terror y el dolor. En lo que respecta al Complejo, se terminaron los debates entre docentes y alumnos, la doble escolaridad, los Directores de Curso, la pedagogía crítica, el "enseñar a pensar"... Las desapariciones, los secuestros, cesanteos y leyes aplicadas, sirvieron de experiencia a aquellos que no estaban dispuestos a aceptar que el "control total", había impregnado todos los ámbitos de la sociedad (58).

Reivindiquemos esta concreta experiencia educativa tal magnitud, como ejemplo de educación argentina y no perdamos de vista que la educación es un "derecho", cada vez más denegado. La creación del Complejo Biblioteca Vigil es una reacción y una contra-respuesta al Gobierno, ya que supo respetar a sus actores institucionales rompiendo con regularidades impuestas, logrando así un proyecto de educación diferente.

\section{Reflexiones finales}

El Complejo Vigil fue ejemplo espectacular de organización barrial y popular, que se sobresalió de los límites impuestos y que permanece aún en el discurso de su gente.

El recorte estuvo enmarcado en el Instituto Secundario, desde su creación en 1970, mediado por la Intervención; hasta la vuelta a la democracia en 1983.

El Proyecto de investigación casi se ve coartado cuando me comunican que los Documentos Curriculares habían sido incinerados por el gobierno militar y sus copias originales permanecían en el Ministerio de Educación sin posible acceso. La salida fue indagar, mediante la empiria sobre el currículum como práctica, entrevistando a personas que, de diferentes maneras, habían estado vinculadas a la Vigil en el período mencionado. La tarea posterior consistió en enfrentar esos registros, pudiendo establecer conexiones y verdades en relación a este enigmático Complejo.

Como educadores sabemos que el contexto ya no es el mismo, ni la realidad tampoco, son otras las preocupaciones del presente, como también lo son las características de nuestro campo de acción. Pero deberemos 
reinventar la educación de las personas en la cotidianeidad de las escuelas, sabiendo que se puede, ya que la investigación lo demuestra.

\section{Notas Bibliográficas}

(1) Schanzer, R. (1999) Paradigmas de los enfoques cuantitativo y cualitativo en investigación social: La combinación de información cuantitativa y cualitativa, Rosario, Papeles de Investigación $N^{\circ} 3$. La autora menciona que en el Paradigma Cualitativo, "(...) la investigación se realiza sobre elementos que no necesariamente son cuantificables, como ser la palabra hablada o escrita y la conducta directamente observable, codificando los datos obtenidos e interpretándolos".

(2) Mc Kernan, J. (1999) Investigación- acción y currículum. Métodos y recursos para profesionales reflexivos, Madrid, Morata. El autor menciona: "El estudio de casos informa sobre un proyecto, innovación o acontecimiento durante un período prolongado de tiempo contando la evolución de un relato o historia".

(3) Por "documentos caseros" nos referimos a archivos manuscritos registrados y elaborados en relación a la organización, a estructura, etc. por personas que tuvieron vinculación con el Complejo Biblioteca Vigil o con el Instituto Secundario en particular y que fueron resguardados en los domicilios. Una gran mayoría de la documentación oficial fue sustraída por los interventores.

(4) En el trabajo original se realizó en el Capítulo I un relevamiento de datos que proporcionen información sobre los orígenes del Complejo, a la vez que se lo inserta en la Historia Argentina. El Segundo Capítulo se basó en la descripción, con algunas acotaciones subjetivas, de nuestro recorte: El Instituto Secundario. El Capítulo III reseñaba brevemente desde la Historia de la Educación, las Políticas Educativas y tendencias Pedagógicas de las décadas de 1960 y 1970. El Capítulo IV trianguló la información, donde además, se concluyó y reflexionó acerca del trabajo de investigación todo.

(5) Naranjo, R. (1990-1993) La Biblioteca Popular Constancio C. Vigil, Rosario, Historias de Aquí a la Vuelta $N^{0} 16$, Ediciones de Aquí a la Vuelta.

(6) Ob. cit. pp. 3-4.

(7) Ob. cit. p. 3.

(8) Constancio $\mathrm{C}$. Vigil fue un escritor uruguayo, reconocido en los medios sociales humildes por sus cuentos infantiles como "La Hormiguita Viajera", "Misia Pepa", "El Mono Relojero", y muchos otros, y además por dirigir en los años '50 "El Gráfico" (de publicación deportiva) y la revista escolar "Billiken".

(9) Ob. cit. p. 8.

(10) Ob. cit. pp. 7-8.

(11) Entre la bibliografía más relevante se puede nombrar a autores como: Humberto Eco, José Pedroni, el santafesino Hugo Gola, el entrerriano Juan Ortiz, María Teresa Nidelcoff, Margaret Mead, Carl Marx, Paulo Freire; John Dewey. Además existían ediciones de su "Editorial Biblioteca" con publicaciones de 
los ya nombrados autores locales y regionales, además de Rubén Naranjo y Raúl Frutos que también organizaban y guiaban la confección de enciclopedias para los alumnos; por nombrar tan sólo dos de sus obras nos podemos remitir a "Santa Fe: el paisaje y los hombres"; y "El Paraná; el pariente del mar".

(12) Comisión Directiva provisoria de la Biblioteca Popular "Constancio C. Vigil" (2005) La Vigil. Una obra de muchos para beneficio de todos que debe continuar..., Rosario, A.V.Ro.S.E.

(13) Naranjo, R. y otros (1974) Santa Fe: el paisaje y los hombres, Rosario, Biblioteca.

(14) Decálogo de los principios educativos de la Biblioteca Popular Constancio C. Vigil:

1. La Biblioteca popular Constancio C. Vigil, en cumplimiento de los fines que le dieron origen, se obliga a organizar, mantener, supervisar y perfeccionar constantemente un sistema educativo que comienza en el Jardín de Infantes y se extiende, por lo menos, a los niveles Primario y Secundario, agregando un parasistema de Educación y Cultura Populares.

2. Organizará el sistema y el parasistema según los principios de la educación permanente, que abarca toda la vida del individuo, desde la primera infancia hasta sus últimos días, y comprende todos los aspectos de su personalidad: intelectuales, morales, sociales, físicos, emocionales y estéticos. En consecuencia desarrollará (además del sistema escolar regular) cursos y actividades de posgrado, de capacitación de actualización y de perfeccionamiento a todos los niveles y para todas las edades.

3. Toda educación que se imparta en las escuelas de Biblioteca, como así mismo toda su actividad cultural, tendrán un solo y único destinatario: el pueblo de la República. No se hará discriminación de ninguna clase. Toda persona residente en el país, cualquiera sea su edad, su sexo, su estado civil, su condición social o económica, su raza, sus convicciones políticas o filosóficas; su religión, su profesión u oficio, puede ser alumno de las escuelas de Biblioteca o enviar sus hijos a ellas, y participar de sus actividades culturales aprendiendo o enseñando en sus aulas, bibliotecas, sala de conferencias y talleres.

4. Toda acción educativa y cultural desarrollada por la Biblioteca Popular C. C. Vigil, sus escuelas y demás dependencias estará al servicio del desarrollo económico, social y cultural de la República, para que cada día sean más en la Argentina los hombres y mujeres que participen en plenitud de los bienes de la civilización y de los frutos de la cultura.

5. El afianzamiento y la consolidación de la nacionalidad argentina, abierta a todos los logros de la cultura universal, pero celosa de su independencia irrenunciable, será finalidad esencial de toda educación que se imparta en Biblioteca. El estudio de los grandes problemas nacionales y la divulgación de sus mejores soluciones, tendrán, por lo tanto, prioridad primera en los planes y programas de sus escuelas e institutos. 
6. La educación que se imparta en todas las escuelas e institutos de Biblioteca será integral, coeducativa, popular, gratuita, laica, no dogmática, científica y asistencial.

7. La institución procurará, en consecuencia, compensar las deficiencias sociales, económicas, culturales y de toda índole, que impiden o dificultan a muchos la iniciación o la continuación de sus estudios, haciendo cuanto esté a su alcance para colocarlos en igualdad de condiciones con los que pueden costeárselos por sí mismos.

8. Las escuelas de Biblioteca procurarán matricular al mayor número posible de alumnos, pero además se esforzarán por retenerlos en sus aulas a lo largo de los diversos ciclos, evitando hasta donde sea posible la deserción y la repetición. Los orientarán, también, hacia la prosecución de los estudios que más se adecuen a sus intereses o hacia a la profesión u oficio más acorde con sus aptitudes. Para ello, Biblioteca organizará y sostendrá un servicio de orientación educativa y vocacional en constante desarrollo y perfeccionamiento.

9. La Biblioteca C. C. Vigil, estimulará preferentemente la investigación y la experimentación pedagógicas, proporcionando los recursos suficientes, con el fin de perfeccionar constantemente los planes de estudios, los programas, los métodos y los medios auxiliares que aseguren una enseñanza racional científica y no dogmática.

10. Las escuelas de Biblioteca ajustarán su actuación a un régimen de evolución permanente y periódica que asegure el perfeccionamiento constante e ininterrumpido de la educación que imparte.

Para asegurar el desarrollo y el mejoramiento permanente de su sistema y de su parasistema educativo, Biblioteca Vigil creará, organizará y sostendrá cuantos institutos sean necesarios, como bibliotecas, museos, observatorios, centros recreativos, campos de deporte, cines, teatros, etc. Todos ellos servirán a las distintas escuelas, pero, además, determinarán sus propios fines y objetivos y se abrirán al pueblo para su utilización y disfrute, erigiéndose en medios de educación permanentes.

(15) Naranjo, R. (1990-1993) La Biblioteca Popular Constancio C. Vigil, Rosario, Historias de Aquí a la Vuelta $N^{\circ} 16$, Ediciones de Aquí a la Vuelta.

(16) Entrevista realizada a Bety, profesora del Instituto Secundario C. C. Vigil.

(17) Frutos, R. (1997) La Biblioteca Popular Constancio C. Vigil, Santa FE, Nuestra Historia No 6, AMSAFE.

(18) Entrevista realizada a Bety, profesora del Instituto Secundario C. C. Vigil: "Si estaba establecido desde el programa oficial que un profesor cobrara -de manera figurativa- seis pesos, nosotros como empleados de Vigil cobrábamos diez".

(19) Naranjo, R. (1990-1993) La Biblioteca Popular Constancio C. Vigil, Rosario, Historias de Aquí a la Vuelta $N^{\circ} 16$, Ediciones de Aquí a la Vuelta. 
(20) En los Consultorios los alumnos eran examinados por un médico deportólogo que colaboraba con el profesor de Educación Física en casos que lo requerían (ante la existencia de problemas lumbares, en las articulaciones o plantas de los pies, entre otros).

(21) Educación formal: se inscribe en ciclos organizados y avalados por el estado que certifica y que lo acredita ante el gobierno correspondiente para proseguir con otro ciclo educativo (...). De "La divisa del nuevo milenio" (s.f.). La Educación Formal en el Complejo se corresponde con las Escuelas y Jardines Oficiales que son parte de nuestro sistema educativo.

(22) Educación no formal: Toda actividad educativa organizada y sistemáticamente realizada fuera de la estructura del sistema educativo formal, para impartir cierto tipo de aprendizaje a ciertos subgrupos de la población, ya sea adultos o niños. De "La divisa del nuevo milenio" (s.f.). En el Complejo Vigil se hace referencia a ella cuando se menciona a la "Universidad Popular", a la que asistían los adultos.

(23) Centro Recreativo y Deportivo en Villa Diego, de 23 has., frente al río Paraná, que contaba con canchas de fútbol, vóleibol, bochas, etc. y camping.

(24) Entrevista realizada a Checha, miembro de la Comisión Directiva del Complejo Constancio C. Vigil.

(25) Diker, G. y Terigi, F. (2008) La formación de maestros y profesores. Hoja de ruta, Buenos Aires, Paidós.

(26) Véase Puiggrós, A. y Lozano, C. (Comp.) (1995) Historia de la Educación Iberoamericana, Buenos Aires, Miño y Dávila.

(27) Puigrrós, A. (2004) Qué pasó en la Educación Argentina. Breve historia desde la Conquista hasta el Presente, Buenos Aires, Galerna.

(28) Recordemos la "Noche de los Bastones Largos" del 29 de julio de 1966. Es aquí donde comienza el éxodo de intelectuales de nuestro país, lo cual se profundiza en el período 1976-83.

(29) Pérez Gómez, A. (1999) La cultura escolar en la sociedad neoliberal, Madrid, Morata. Este autor describe a la escuela como un "espacio ecológico de cruces de culturas" diciendo: " (...) entre las propuestas de la cultura pública, alojada en las disciplinas científicas, artísticas y filosóficas; las determinaciones de la cultura académica reflejada en las concreciones que constituyen el currículum, los influjos de la cultura social, constituidos por los valores y prácticas hegemónicas del escenario social; las presiones cotidianas de la cultura escolar, presente en las normas, roles, rutinas y ritos propios de la escuela como institución social específica; y las características de la cultura privada, adquirida por cada alumno a través de la experiencia en los intercambios espontáneos con su entorno (...)".

(30) Brovelli, M. (2006) Cambio e innovaciones educativas: Representaciones y contextos, Rosario, Revista de la Escuela de Ciencias de la Educación $\mathrm{N}^{\circ} 1$ Año 2, Facultad de Humanidades y Artes (UNR), pp. 71-92, Laborde.

(31) Fernández, L. (s.f.) Instituciones educativas. Dinámicas institucionales en situaciones críticas, Buenos Aires, Paidós. 
(32) Torres, C. A. (Comp.) (2002) Paulo Freire y la Agenda de la Educación Latinoamericana en el Siglo XXI ( $2^{\circ}$ Ed.), Buenos Aires, FLACSO.

(33) Remitirse a la descripción sobre Currículas, Alumnos y Profesores.

(34) Entrevista a Ma. Elena Albaizeta, profesora en el Instituto Secundario Constancio C. Vigil.

(35) España, A. y Gentiletti, G. (2006) Referentes del arte en la enseñanza de las ciencias sociales, Rosario, Revista Novedades Educativas $N^{\circ} 188$, pp. 8286.

(36) Puiggrós, A. y Lozano, C. (Comp.) (1995) Historia de la Educación Iberoamericana, Buenos Aires, Miño y Dávila.

(37) Ansaldi, W. (2006) El silencio es salud. La dictadura contra la política. En Argentina 1976-2006. Entre la sombra de la dictadura y el futuro de la democracia, Rosario, Homo Sapiens.

(38) Ob. cit. pp. 100-101.

(39) Para ampliar véase: Solari, T. (Comp.) (2008) Biblioclastía, Buenos Aires, EUDEBA.

(40) Puigrrós, A. (2004) Qué pasó en la Educación Argentina. Breve historia desde la Conquista hasta el Presente, Buenos Aires, Galerna. Esta autora menciona: "Con la categoría de "subversión" se refiere explícita e implícitamente a las acciones reivindicativas de la clase obrera y a los ataques a la propiedad, así como a la desjerarquización de los roles tradicionales (generacionales, sexuales, de clases, etc.) todo lo cual, considerado expresión de la agresión marxista internacional, se extiende a la totalidad del campo democrático y popular".

(41) Triple A: Alianza Anticomunista Argentina. Era una banda parapolicial fundada y liderada por López Rega, quien fuera Ministro de Bienestar Social y miembro de la Policía Federal.

(42) Frutos, R. (1997) La Biblioteca Popular Constancio C. Vigil, Santa Fe, Nuestra Historia No 6 , AMSAFE.

(43) Rodrigazo: Shock económico provocado por el Ministro de Economía de Isabel Perón, Clestino Rodrigo. Éste, fiel a la ortodoxia liberal, aplicó un paquete de medias de golpe, provocando una verdadera crisis económica, conocida como "el Rodrigazo". Ello desató un estallido espontáneo y masivo que trajo aparejado huelgas generales, ocupaciones de fábricas y movilizaciones. Entre marzo del ' 75 y marzo del ' 76 , los precios subieron el $566,3 \%$.

(44) Un miembro de Vigil nos comentaba en la entrevista: “(...) nosotros teníamos la rifa en marcha, y no nos autorizaron a aumentar las cuotas... entonces un auto... que antes lo cubrías con algunas cuotas de la rifas, ahora no le podíamos hacer frente con nada, los precios aumentan algo así como el 800 $\%$... comenzamos a deber los premios, teníamos muchísimos cuentas... (...) y todas esas ayudas que el gobierno les da a las empresas cuando están mal económicamente, a Vigil nunca se las dieron (...)".

(45) (...) empiezan a vender los bienes de la Vigil... se venden los talleres donde está Ledesma ahora al lado de la escuela primaria, venden las sucursales que 
habíamos comprado para bibliotecas en Rosario, casas que teníamos en Santa $\mathrm{Fe}$, en San Juan, Mendoza, que eran provincias donde se vendían también las rifas de Vigil y teníamos casas compradas... un edificio en la calle Dorrego, que estaba en construcción, poder sortear esos departamentos... y que si a mí me piden opinión sobre el por qué se intervino la Vigil... primero porque era cuestionada políticamente, pero fundamentalmente para poder quedarse con sus bienes, para poder llenarse los bolsillos...

Otra de las personas entrevistadas describe al respecto:

(...) lo que pasaba es que había algo más importante que el superávit económico, había un superávit intelectual con el que los militares no estaban de acuerdo... eso fue algo que marcó, porque en aquella época, todo lo que fuese bien común, social, popular, era subversivo (...) y había que cortarlo de raíz y... desde mi humilde manera de pensar eso fue lo que hizo que se interviniera Biblioteca Vigil... ellos arrasaron con todo lo que pudieron...

(46) Comisión Directiva provisoria de la Biblioteca Popular "Constancio C. Vigil" (2005) La Vigil. Una obra de muchos para beneficio de todos que debe continuar..., Rosario, A.V.Ro.S.E.

(47) Schlemenson, A. (1993) Análisis organizacional y empresa unipersonal, Buenos Aires, Paidós.

(48) Ob. cit. pp. 233-234.

(49) Celia Díaz, alumna de 16 años desaparecida en enero de 1977.

(50) Este sistema funciona con una ficha en cada libro donde quedan registrados todos los datos de sus lectores.

(51) Frutos, R. (1997) La Biblioteca Popular Constancio C. Vigil, Santa Fe, Nuestra Historia $\mathrm{N}^{\circ} 6$, AMSAFE.

(52) Entrevista realizada a Bety, profesora del Instituto Secundario C. C. Vigil: "Me hicieron las mil y una, de 15 horas de trabajo que tenía en Vigil, me redujeron a 8 y me hacían ir tres o cuatro veces por semana (...)".

(53) Naranjo, R. (1990-1993) La Biblioteca Popular Constancio C. Vigil, Rosario, Historias de Aquí a la Vuelta $N^{\circ} 16$, Ediciones de Aquí a la Vuelta.

(54) Ossanna, E. (Coord.) (1997) Tomo VII: La Educación en las provincias (19451985). En Puiggrós, A. (Dir.) Historia de la Educación Argentina, Buenos Aires, Galerna.

(55) Entrevista realizada a Checha, miembro de la Comisión Directiva del Complejo Constancio C. Vigil.

(56) Es interesante aclarar que para algunos de los miembros de Vigil la Biblioteca Eurodo Díaz, a la vez que usurpa terreno a Vigil; sufre también un desarraigo, ya que la trasladaron de su lugar originario (Calle 9 de Julio, de la que no se precisa dirección), pero se reconoce que colabora en la protección de gran cantidad de material bibliográfico de Biblioteca Vigil.

(57) Naranjo, R. (1990-1993) La Biblioteca Popular Constancio C. Vigil, Rosario, Historias de Aquí a la Vuelta № 16, Ediciones de Aquí a la Vuelta.

(58) Resulta de gran importancia comentar brevemente que con la vuelta a la democracia, en el año 1983, Vigil pasa a pertenecer al gobierno provincial. 
Los vecinos organizan una Comisión de recuperación y pese a pedidos de audiencias no se obtienen respuestas. Documentos pertenecientes a la Institución duplicados en el Departamento de Enseñanza Privada del Ministerio de Educación fueron peticionados mediante los tribunales, sin conseguir respuestas positivas.

\section{Referencias Bibliográficas}

- $\quad$ Anales de Legislación Argentina: Tomo XX A. (1960).

- Ansaldi, W. (2006) El silencio es salud. La dictadura contra la política. En Argentina 1976-2006. Entre la sombra de la dictadura y el futuro de la democracia, Rosario, Homo Sapiens.

- $\quad$ Apple, M. (1987) Ideología y Currículum. Madrid, Akal.

- Brovelli, M. (2006) Cambio e innovaciones educativas: Representaciones y contextos, Rosario, en Revista de la Escuela de Ciencias de la Educación №1 Año 2, Facultad de Humanidades y Artes (UNR), pp. 71-92, Laborde.

- Brovelli, M. (1997) Desafíos del Currículum Universitario para una educación Superior en Transformación. Rosario.

- Carr, W. y Kemmis, S. (1988) Teoría Crítica de la Enseñanza, Barcelona, Martínez Roca.

- Comisión Directiva provisoria de la Biblioteca Popular "Constancio C. Vigil" (2005) La Vigil. Una obra de muchos para beneficio de todos que debe continuar..., Rosario, A.V.Ro.S.E.

- Contreras, J. (1990) La Didáctica y los procesos de enseñanza y aprendizaje. En Enseñanza, Curriculum y Profesorado. Madrid, Akal.

- Cullen, C. (1997) Críticas de las razones de educar. Buenos Aires, Paidós.

- España, A. y Gentiletti, G. (2006) Referentes del arte en la enseñanza de las ciencias sociales. Rosario, en Revista Novedades Educativas № 188, pp: 82-86.

- Fernández, L. (s.f.) Instituciones educativas. Dinámicas institucionales en situaciones críticas. Buenos Aires, Paidós.

- Freire, P. (2008) La educación como práctica de la libertad $\left(2^{\circ}\right.$ Ed.), Buenos Aires, Siglo XXI.

- Freire, P. (2002) Pedagogía de la Esperanza. Un reencuentro con la Pedagogía del oprimido. Buenos Aires, Siglo XXI.

- Frutos, R. (1997) La Biblioteca Popular Constancio C. Vigil, Santa Fe, Nuestra Historia N ${ }^{\circ} 6$, AMSAFE.

- Giroux, H. (1990) Los Profesores como Intelectuales. Buenos Aires, Paidós.

- Grundy, S. (1987) Producto o praxis del currículum. Madrid, Morata.

- lazzetta, O. (2006) Los desencuentros entre estado y democracia en el pensamiento latinoamericano. En Democracias en busca de Estado. Ensayos sobre América Latina. Rosario, Homo Sapiens. 
- Kemmis, S. (1988) El Currículum: más allá de la Teoría de la Reproducción. Madrid, Editorial Morata.

- Malla; J. (2006) Historia del Barrio Tablada y de la Biblioteca C. C. Vigil, Rosario, Asociación Vecinal Rosario Sud Este -A.V.Ro.S.E.

- Mc Kernan, J. (1999) Investigación-acción y currículum. Métodos y recursos para profesionales reflexivos, Madrid, Morata.

- Naranjo, R. y otros (1974) Santa Fe: el paisaje y los hombres. Rosario, Biblioteca.

- Naranjo, R. (1990-1993) La Biblioteca Popular Constancio C. Vigil, Rosario, Historias de Aquí a la Vuelta No 16, Ediciones de Aquí a la Vuelta.

- Naranjo, R. y Frutos R. (2006) Tercera Parte. Capítulo XIX: El genocidio blanco. La Editorial Biblioteca Vigil, Rosario, en Kauffman, C. Dictadura y Educación. Los textos escolares en la historia Argentina reciente. Buenos Aires, Miño y Dávila.

- O`Donnell, G. (1996) El Estado Burocrático Autoritario. Triunfos, derrotas y crisis. Buenos Aires, Editorial de Belgrano.

- $\quad$ Ossanna, E. (Coord.) (1997) Tomo VII: La Educación en las provincias (194510985), en Puiggrós, A. (Dir.) Historia de la Educación Argentina. Buenos Aires, Galerna.

- Pérez Gómez, Á. (1999) La cultura escolar en la sociedad neoliberal, Madrid, Morata.

- Pico, F. (2006) Memoria histórica para adolescentes. Dictadura y derechos humanos en Argentina. Rosario, Homo Sapiens.

- Puiggrós, A. y Lozano, C. (Comp.) (1995) Historia de la Educación Iberoamericana. Buenos Aires, Miño y Dávila.

- Puigrrós, A. (2004) Qué pasó en la Educación Argentina. Breve historia desde la Conquista hasta el Presente. Buenos Aires, Galerna.

- Schanzer, R. (1999) Paradigmas de los enfoques cuantitativo y cualitativo en investigación social: La combinación de información cuantitativa y cualitativa, Rosario, Papeles de Investigación № 3 .

- Schlemenson, A. (1993) Análisis organizacional y empresa unipersonal. Buenos Aires, Paidós.

- Schwab, J. (1983) La enseñanza, su teoría y su práctica. Madrid, Akal.

- Torres, C. A. (Comp.) (2002) Paulo Freire y la Agenda de la Educación Latinoamericana en el Siglo XXI ( $2^{\circ}$ Ed.), Buenos Aires, FLACSO.

- Tyler, R. (1973) Principios Básicos del Currículo. Buenos Aires, Troquel.

- Artículos de Diarios:

- Democracia del litoral, 19/03/1984: La Vigil - Capítulo I. Aquel carbonero..., Rosario, PASA, p. 4.

- Democracia del litoral, 20/03/1984: La Vigil - Capítulo II. ¡A toda marcha!, Rosario, PASA, p. 4.

- Democracia del litoral, 21/03/1984: La Vigil - Capítulo III. Nuevos intentos de crecimiento en 1966, Rosario, PASA, p. 4. 
- Democracia del litoral, 22/03/1984: La Vigil - Capítulo IV. La rifa: de película..., Rosario, PASA, p. 4.

- Democracia del litoral, 23/03/1984: La Vigil - Capítulo V. El observatorio, Rosario, PASA, p. 4.

- Democracia del litoral, 26/03/1984: La Vigil - Capítulo VI. Una historia de libros, Rosario, PASA, p. 4.

- Democracia del litoral, 28/03/1984: La Vigil - Capítulo VII. Un Secundario diferente, Rosario, PASA, pp. 4-5.

- La Capital, 28/10/2004: La Vigil cumple mañana 34 años. Escuela que hizo escuela, Rosario, p. 4.

- La Capital, 13/09/1981.

- La Capital, 26/02/2007: Cientos de personas clamaron por la reapertura de la biblioteca Vigil, Rosario, p. 3.

- La Capital, SEÑALES, 28/05/2006: La gesta de una gran empresa cultural, Rosario, pp. 4-5.

- Rosario/12, 02/03/1997: A veinte años de la intervención militar. La Vigil permanece, señala un camino, Rosario, p. 10.

- $\quad$ Rosario/12, 15/04/1998: Historia de un telescopio, Rosario, p. 8.

- Rosario/12, 22/12/1998: Más allá del Observatorio de la Vigil, Rosario, p. 2.

- Rosario/12, 06/01/2001: Aquella biblioteca, Rosario, p. 8.

- Rosario/12, 19/10/2004: Estafa de varios millones, Rosario, p. 13.

- Rosario/12, 25/02/2007: A 30 años de la Intervención militar de la Biblioteca Vigil, Rosario, p. 8.

- Rosario/12, 25/08/2007: La normalización de la biblioteca Vigil, Rosario, p. 3.

- Rosario/12, 18/10/2007: Vigil resiste, Rosario, p. 2. 